\title{
Entre os silêncios da vida e seus volumes: a delicadeza de saber escutar
}

\section{Between the silences of life and its volumes: the delicacy of knowing how to listen}

https://doi.org/10.34112/2317-0972a2021V39n83p169-173

Cristiane Guimarães ${ }^{1}$

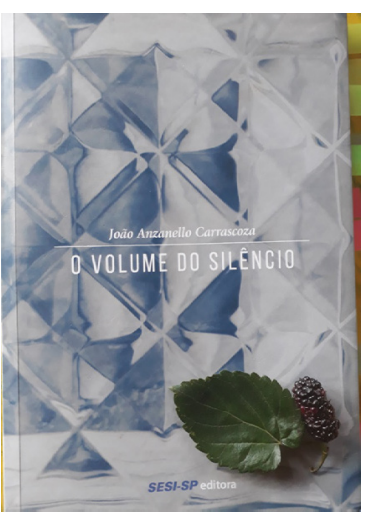

CARRASCOZA, João Anzanello. O volume do silêncio. São Paulo: SESI-SP editora, 2017.

Há uma beleza singular em percorrer os escritos de um autor em momentos diversos de suas escritas através dos vãos de sentido deixados. Como buracos nas fechaduras, é como se pudéssemos espiar, curiosos, uma forma de dança ou um caso de amor, enevoados, é claro, pela reescrita incessante rascunhada nos processos de leitura entre espaços, tempos e vidas que se entrelaçam.

O livro O volume do silêncio, de João Anzanello Carrascoza foi lançado em 2017 pela editora SESI-SP e reúne 17 contos de diversos tempos do autor, reorganizados agora em volume único. Seus contos me ajudaram a ancorar as reflexões da tese ${ }^{2}$ em porto que versa a possibilidade de escrever a vida encenada no encontro do cotidiano com a memória e a poesia.

O volume dos contos é único, mas os volumes dos silêncios que ele narra não o são. São muitos volumes, escutados nos tons ora poéticos e ora cinzentos da vida.

1. Universidade Federal de Santa Catarina/ Rede Municipal de Educação de Florianópolis.

2. A pesquisa de doutorado Poéticas da vida na escola: um inventário de afetos foi defendida no Programa de Pós-graduação em Educação, na Universidade Federal e Santa Catarina, com orientação do Prof. Dr. Leandro Belinaso. 
Ao ler o livro, é como se o autor viesse laboriosamente esculpindo, ao longo dos anos e da matéria prima da vida, a capacidade de perceber o silêncio, escutá-lo, lê-lo e também de tentar narrá-los em palavras. Parece que são anos tecendo os limites que abismam as palavras e seus lados de fora. Ou as palavras e seus dentros. Aqueles núcleos em que o código beija o vazio da matéria e deixa que algo nasça. Os encontros e os silêncios. As solidões e os silêncios. Os corpos e os silêncios que pairam antes das palavras, como ensina o autor. Ou o silêncio contido em um ruído ou no murmúrio. Ou na gagueira que emerge nas palavras malditas e incompreendidas. Ou ainda o silêncio presente nas passagens das estações, nas nuvens e no vento. $\mathrm{O}$ silêncio de um dia que se despede em explosão de cores. $\mathrm{O}$ silêncio diante do que não entendemos e nem alcançamos. O silêncio diante das vergonhas humanas.

O livro reúne em tons diversos o silêncio manifesto, aquele lido nas expressões diversas humanas e além humanas e que podem (ou não às vezes) serem escutadas. Não decodificadas como intentam aqueles que acreditam no sentido guardado e escondido das palavras, mas escutados com o corpo inteiro: a leitura dos mundos e das gentes, como aprendi a compreender com o próprio autor e com Paulo Freire (2015).

Carrascoza (2014, p. 111) define "uma metáfora só é uma metáfora porque diz o que não se pode dizer de outra maneira, é a tentativa de driblar o incomunicável”. Com o autor aprendi a ler gente, assim como aprendi com Paulo Freire (2015) que não lemos apenas as palavras, mas lemos as palavras porque lemos o mundo e lemos o mundo porque as palavras nos ajudam a fazê-lo, assim como outras linguagens o fazem como mediadoras. Aprendi com eles também que as palavras têm memória e também nelas moram silêncios de muitos tempos e espaços, na teia de vozes, infinita, humana e além humana.

Por isso, ao ler os contos é possível perceber que o silêncio amarra belamente as narrativas, aparece aqui e acolá, tecendo passagens e encontros entre personagens, seus entornos e seus afetos.

Michèle Petit (2013) fala das linhas fulgurantes que lemos durante a vida e que nos marcam ou nas palavras de Roland Barthes (2018) nos pungem. Os contos presentes neste volume são assim. Houve momentos que li vários contos em um só dia e um só fôlego. Houve contos que precisei de dias para acalmar meu coração e respirar, tamanho rio de afetos que se movimentaram em minhas águas. Ouvi vozes dos narradores e outras vozes que converso na tese, como estudantes, professores aposentados, anciãos do bairro. Li imagens poéticas e cenas carregadas de 
uma melancolia outonal em tempos de solidões nas janelas, inimigos invisíveis e assassinos televisionados pelas luzes mercantis.

O livro é uma prosa de silêncios que conversam: o silêncio de uma viagem ou da paisagem entrecortada pelas marchas trocadas do motor de um Voyage, como escreve Carrascoza (2017, p. 11): "O pai vê a paisagem ao seu lado, um pasto ralo que se espraia, silenciosamente, os bois como imóveis porcelanas ruminando". $\mathrm{O}$ menino lê o silêncio que mora nas raízes das árvores. O silêncio que vem depois de um estampido de uma arma e que invade a noite e as brincadeiras de um grupo de amigos. O silêncio em forma de um ruído de um pião que espera a vida chegar e paira na película de água do cotidiano: tudo se move e tudo em espera.

Há o silêncio dos encontros. Os silêncios que abismam gentes, irmãos, gerações, amigos e enamorados. $\mathrm{O}$ volume do silêncio aumenta em contato com espantos: $\mathrm{o}$ volume do silêncio de dois irmãos, cujos rios se separaram a caminho do mar. $\mathrm{Ou}$ o silêncio que reina entre aqueles que se conhecem demais. Não podemos parar e não podemos escutar. Porque este silêncio dói e lateja em frente à televisão: "À noite, quando o céu é mais misterioso, quando a vida revela seus segredos, nos acomodamos, em silêncio diante da televisão. [...] Ligamos apenas porque não suportamos a solidão", poetiza o narrador (CARRASCOZA, 2017, p. 64).

Há, ainda os silêncios da meninice: um passeio na casa da avó. Uma chamada diferente na escola que começou a ser ouvida ainda de manhã, em um adeus feito sem jeito, às pressas. A menina, tão jovem, já sabia ler, mesmo que não entendesse que sentimento era aquele de estar na sala de aula e não estar, como conta: "A amiga cutucou. O que vocêtem? Renata enveredara-se pelas linhas de sua própria matéria, tão sua que por vezes lhe parecia de outra, e respondeu, sem convicção, Nada." (CARRASCOZA, 2017, p. 146-147, grifos do autor). Como não se lembrar de tantas ausências-presentes nas salas de aulas escrevendo suas vidas em silêncio.

Se soubéssemos ler melhor os silêncios, as palavras doeriam menos ou faríamos melhor uso delas? Às vezes paramos diante do outro, mas não conseguimos ouvir nada além de nossa própria voz. Mas o "abecedário do silêncio" não nos é apresentado senão dentro dos silêncios das horas entre verbos diários e entre as vírgulas de cada respiração no texto da vida. O narrador do Caderno de um ausente tentou alertar Bia, sua filha, que estava chegando ao mundo, sobre a importância do silêncio, de saber lê-lo ou escutá-lo: "se eu pudesse, eu te ensinava todo o abecedário do silêncio antes da fala, eu desaprenderia a falar e adotaria como 
língua todo o (meu) humano silenciar; [...] é no silêncio que um corpo clama pelo outro." (CARRASCOZA, 2014, p. 111-113)

E há as palavras entrecortadas pelos silêncios das partidas, despedidas, ausências, chegadas, visitas inesperadas e visitas encenadas. Há irmãs e irmãos, silêncios expulsos da infância, tecendo encontros e timbres indecisos de voz. O silêncio que desenha o cotidiano, mas que também prenuncia o adeus, como descreve Carrascoza (2017, p. 192): “[...] o silêncio alargava vagarosamente as paredes ao redor, a sala, a casa inteira". O silêncio que golpeia a vida vivida nos trechos, levando embora uma irmã que desabrochava em festa. $O$ silêncio diante do outro que não existe mais, senão na memória. $\mathrm{O}$ silêncio de uma noite diferente sem luz elétrica.

Mas há também um silêncio de uma manhã que nasce: exuberante no turvar das cores. A face rubra e desavergonhada do dia que acorda. Um galo com bicos presos, mas com mil cantos guardados para um novo dia. Um silêncio amarrado atravessando uma fronteira entre a vida e a morte. $\mathrm{O}$ silêncio das travessias perigosas da vida beija também o silêncio alegre do jardim da casa da avó.

De silêncio em silêncio, aceitamos as horas e suas cinzas, mesmo sem tempo para celebrarmos o adeus e catalogarmos em potinhos na estante da sala os instantes poéticos de cada uma delas.

Uma vez escrevi sobre o silêncio dos pescadores da tainha, que ficam postos diante do mar esperando os cardumes reluzirem no horizonte da praia. Nos dias de hoje, e ao me encontrar com a prosa poética e cotidiana de Carrascoza (2017), neste e em outros livros, posso ler também formas de ensinamentos que andam fora de moda nos currículos da vida. Será que conseguimos ler ou escutar o silêncio sensível que habita o coração das narrativas de João Anzanello Carrascoza?

Há contos em volume mínimo, beirando o rés-do-chão cotidiano. Há contos que narram encontros e desencontros familiares, maritais, sociais. Há contos que nos tiram todas as palavras, a respiração e o chão. Outros que nos lançam para as estrelas. Há ainda aqueles que nos fazem voar para um lugar silencioso, secreto e só nosso. Há contos que nos ensinam não apenas a ouvir o silêncio, mas regular seus volumes dentro de nós. Você consegue ouvir?

\section{REFERÊNCIAS}

BARTHES, Roland. A câmara clara: notas sobre a fotografia. Trad. Júlio C. Guimarães. 7. ed. Rio de Janeiro: Nova Fronteira, 2018. 
CARRASCOZA, João Anzanello. Caderno do um ausente. São Paulo: Cosac Naify, 2014.

CARRASCOZA, João Anzanello. O volume do silêncio. São Paulo: SESI-SP Editora, 2017.

FREIRE. Paulo. Pedagogia da indignação: cartas pedagógicas e outros escritos. In: FREIRE, A. M.

A. (Org.). 2. ed. São Paulo: Paz e Terra, 2015.

PETIT, Michèle. Leituras: do espaço íntimo ao espaço público. Trad. Celina O. de Souza. São Paulo:

Editora 34, 2013.

\section{SOBRE A AUTORA}

Cristiane Guimarães é mãe do João, da Melissa e da Flora. Graduada em Letras, pela Universidade Estadual de Maringá, no Paraná. Tem Mestrado em Educação, no Programa de Pós-graduação em Educação, na Universidade Federal de Santa Catarina. Atualmente é doutoranda no mesmo Programa. É professora de Língua Portuguesa na Rede Municipal de Educação de Florianópolis. Pesquisa com o grupo Tecendo Cultura Arte e Educação, na Universidade Federal de Santa Catarina, as relações entre escrita, biografia, memória e poesia.

E-mail: turmasdacris@gmail.com. ORCID: https://orcid.org/oooo-0002-8402-8216.

Texto aprovado em 24/10/2021. 